\title{
RESGATE DA HISTÓRIA DOS POVOS AFRICANOS NO \\ SUL DE MINAS: ADAPTAÇÃO DO “MAPPA DE TODO O \\ CAMPO GRANDE" PARA O ATLAS ESCOLAR DE \\ ALFENAS (MG)
}

\author{
Márcio Abondanza Vitiello ${ }^{1}$ \\ Luiz Carlos dos Santos Júnior² \\ Mara Helena Lopes Ferreira ${ }^{3}$
}

RESUMO: O mapa é uma das representações gráficas mais antigas conhecidas pela humanidade. No Brasil, os registros mais antigos datam do século XVI, decorrente do processo de expansão colonial portuguesa. Nesse artigo, apresentamos o processo de adaptação do "Mappa de todo o Campo Grande, cabeceiras do rio São Francisco e Goiazes", com o objetivo de torná-lo mais inteligível aos olhos daqueles que iniciaram o processo de alfabetização cartográfica e que terão acesso ao Atlas Escolar de Alfenas. A carta original versa sobre a presença de dezenas de grupos quilombolas identificados no decorrer da interiorização bandeirante e que foram mapeados entre 1760 e 1763. Assim, com o objetivo de dar relevância a esse registro histórico, o Atlas Escolar de Alfenas trará uma nova versão deste mapa a fim de reafirmá-lo como herança da existência desses povos na região Sul de Minas Gerais, bem como suas lutas e resistências. Para tal, foi utilizado o sotware Adobe Photoshop versão 22.4.3, e seus recursos básicos de edição de imagem para evidenciar a legenda, o norte geográfico, corrigir imperfeições e acrescentar descrições. Por fim, o mapa adaptado foi incorporado ao Atlas, dialogando com textos, ilustrações e sugestões pedagógicas estabelecendo uma ruptura aos atlas tradicionais.

PALAVRAS-CHAVE: Material Didático; Quilombolas; Cartografia Social; Cotidiano Escolar; Povos Africanos

\footnotetext{
1 Docente do Instituto de Ciências da Natureza, Universidade Federal de Alfenas; e-mail: marcio.vitiello@unifal-mg.edu.br

2 Discente de Geografia Licenciatura, Universidade Federal de Alfenas; e-mail: luiz.santos@souunifal-mg.edu.br

3 Discente de História Licenciatura, Universidade Federal de Alfenas; e-mail: mara.ferreira@sou.unifal-mg.edu.br
} 


\title{
BRINGING OUT THE HISTORY OF THE AFRICAN PEOPLE IN THE SOUTH OF MINAS: ADAPTATION OF THE “MAPPA DE TODO O CAMPO GRANDE" OF THE SCHOOL ATLAS OF ALFENAS (MG)
}

\begin{abstract}
The map is one of the oldest graphical representations produced by humans. In Brazil, the oldest records date from the 16th century, resulting from the process of Portuguese colonial expansion. In this article, we present the adaptation process of the "Mappa de todo o Campo Grande, cabeceiras do rio São Francisco e Goiazes", with the objective of making it more intelligible to those who started the cartographic literacy process and who will have access to the School Atlas of Alfenas. The original map is about the presence of dozens of quilombola groups identified during the Bandeirante interiorization and that were mapped between 1760 and 1763. Thus, in order to give relevance to this historical record, the School Atlas of Alfenas will bring a new version of this map in order to reaffirm it as a legacy of the existence of these peoples in the southern region of Minas Gerais, as well as their struggles and resistance. For that, Adobe Photoshop version 22.4.3 was used, and its basic image editing resources were used to highlight the legend, geographic north, correct imperfections and add descriptions. Finally, the adapted map was incorporated into the Atlas, dialoguing with texts, illustrations and pedagogical suggestions, establishing a break with the traditional atlas.
\end{abstract}

KEYWORDS: Didactic Material; Quilombolas; Social Cartography; Daily School; African Peoples

\section{RESCATE DE LA HISTORIA DEL PUEBLO AFRICANO EN EL SUR DE MINAS: ADAPTACIÓN DE “MAPPA DE TODO O CAMPO GRANDE” PARA EL ATLAS ESCOLAR DE ALFENAS (MG)}

RESUMEN: El mapa es una de las representaciones gráficas más antiguas conocidas por la humanidad. En Brasil, los registros más antiguos datan del siglo XVI, resultado del proceso de expansión colonial portuguesa. En este artículo presentamos el proceso de adecuación del "Mappa de todo el Campo Grande, cabeceras de los ríos São Francisco y Goiazes", con el objetivo de hacerlo más inteligible para quienes iniciaron el proceso de alfabetización cartográfica y que tendrán acceso al Colegio Atlas de Alfenas. La carta original trata sobre la presencia de decenas de grupos quilombolas identificados durante la interiorización bandeirante y que fueron mapeados entre 1760 y 1763. Así, para dar relevancia a este registro histórico, el Atlas Escolar de Alfenas traerá una nueva versión de este mapa para reafirmarlo como legado de la existencia de estos pueblos en la región sur de Minas Gerais, así como de sus luchas y resistencias. Para eso, se utilizó Adobe Photoshop versión 22.4.3, y sus recursos básicos de edición de imágenes se utilizaron para resaltar la 
leyenda, el norte geográfico, corregir imperfecciones y agregar descripciones. Finalmente, se incorporó al Atlas el mapa adaptado, dialogando con textos, ilustraciones y sugerencias pedagógicas, estableciendo una ruptura con los atlas tradicionales.

PALABRAS CLAVE: Material didáctico; Quilombolas; Cartografía social; Escuela diaria; Pueblos africanos

\section{INTRODUÇÃO}

Desde suas origens, os conhecimentos cartográficos denotam um exercício de poder, seja para representar rotas de caça ou localizar fontes de recursos naturais, vitais para a sobrevivência humana; seja como forma de delimitação territorial. Na história da humanidade, diferentes civilizações fizeram uso da cartografia: navegadores gregos e fenícios mapeavam portos para facilitar suas rotas comerciais; o Império Romano, visando a ampliação de seu domínio, cartografava itinerários, localizando serras, rios e estradas que pudessem facilitar o deslocamento de seu exército (JOLY, 1990) e foi, com o advento das Grandes Navegações, a partir do século XV, que a cartografia se consolidou em prol da conquista de novos territórios ultramarinos pelos europeus.

De acordo com Freitas (2005), no século XV a busca de poder e novos recursos alavancaram o aprimoramento de técnicas e instrumentos cartográficos. Assim, os mapeamentos foram realizados de acordo com os interesses das classes dominantes, majoritariamente para questões geopolíticas ou como forma de repressão de minorias.

No Brasil, essa ação pode ser evidenciada por meio da análise de centenas de registros cartográficos feitos pelos colonizadores portugueses e bandeirantes paulistas no período colonial. As representações cartográficas foram atreladas às batalhas, disputas por territórios, submissão de povos e rotas de interiorização que formariam o território brasileiro. Um exemplo deste foi a elaboração do "Mappa de todo o Campo Grande, tanto da parte da conquista 
que parte com a campanha do rio Verde e S. Paulo, como de Piuhy Cabeceiras do S. Francisco e Goyazes", do capitão Antônio Francisco França, feito entre 1760 e 1763, com o intuito de localizar e exterminar todos os quilombos existentes na região então denominada de Campo Grande, que incluía as margens do rio Grande, no Sul e Sudoeste de Minas Gerais (DISTRITO FEDERAL, 2021).

Atualmente, esse mapa - que traz com extraordinário detalhe a localização de 24 grupos de comunidades quilombolas no Sul de Minas, em meados do século XVIII, anteriores às fundações de muitas vilas e cidades sul mineiras pertence à Coleção da Família Almeida Prado, sob custódia do Instituto de Estudos Brasileiros da Universidade de São Paulo. Foi fotografado em 1992 por Tarcísio José Martins e disponibilizado na plataforma digital do Arquivo Público do Distrito Federal, servindo de base para este estudo e sendo incorporado ao Atlas Escolar de Alfenas, como forma de protagonizar a presença africana nessa região e valorizar um ensino antirracista em acordo com a Lei n 11.645/08.

A RESPEITO DO ATLAS ESCOLAR GEOGRÁFICO, HISTÓRICO E CULTURAL DE ALFENAS

A proposta de elaboração do Atlas Escolar surge de um projeto de extensão, no ano de 2020, coordenado pelo Prof. Dr. Márcio Abondanza Vitiello em parceria com outros docentes, discentes bolsistas e voluntários. Sendo Alfenas o "berço" da Universidade Federal de Alfenas (UNIFAL- MG), a possibilidade de se produzir um material didático para as escolas públicas do Município, se tornou o pilar principal do projeto. O Atlas, portanto, emerge da necessidade de materiais didáticos em escalas local e regional, na maioria das vezes não contempladas nos livros didáticos distribuídos pelo Programa Nacional do Livro Didático (PNLD). Buscou-se, com essa publicação (VITIELLO e SANTOS JÚNIOR, 2021) Figura 1, evidenciar a relação sociedade e natureza por 
meio da análise de paisagens, lugares, territórios e territorialidades alfenenses e sul mineiras.

Neste sentido, a proposta se concretizou a partir de pesquisas e de um trabalho coletivo que foi desenvolvido ao longo de dois anos. Dentre as dezenas de temas abordados, especial atenção foi dada à presença dos povos africanos, em conformidade com a Lei 11.645/2008, que torna obrigatório o ensino da história afro-brasileira nas escolas do ensino básico em nosso país. Para relevar aspectos pouco evidentes nos livros didáticos tradicionais, foram utilizados preceitos da cartografia social. De acordo com Santos (2016, p.03), "tanto no Brasil quanto nas mais diversas partes do mundo, objetos cartográficos vêm sendo utilizados como leituras (sociais) do território que são confrontadas às leituras oficiais e/ou de atores hegemônicos, mas também como instrumentos de (fortalecimento de) identidade social e de articulações políticas".

Figura 1 - Capa do Atlas escolar, geográfico, histórico e cultural de Alfenas 


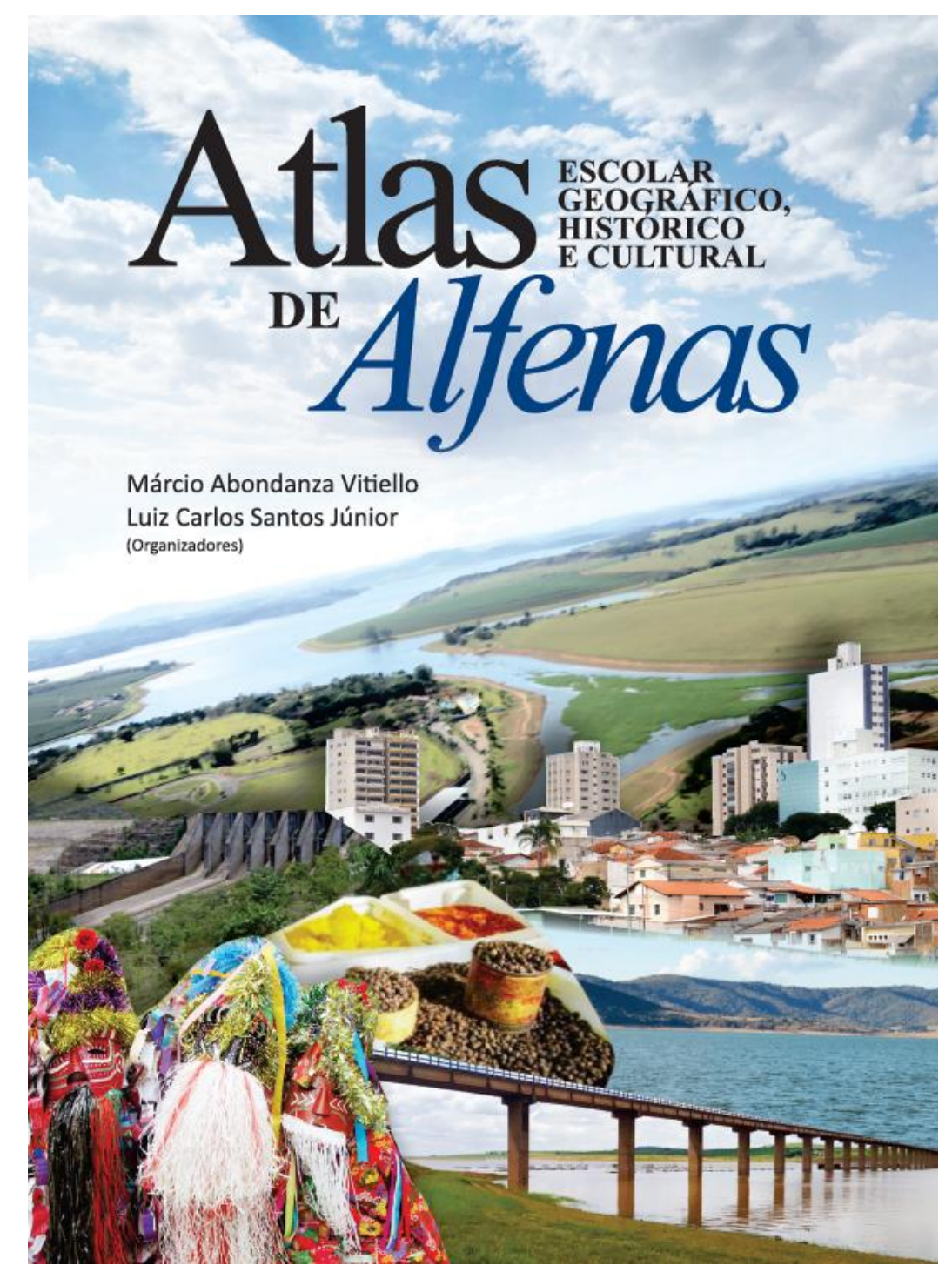

Fonte: Vitiello e Santos Júnior (2021)

Portanto, o presente artigo visa não só contemplar o processo de adaptação do mapa, como também evidenciar a luta territorial dos povos quilombolas. Logo, um movimento contrário ao apagamento de sua (re)existência e luta nos Atlas escolares, na sua maioria reprodutores da cartografia hegemônica.

\section{OS POVOS AFRICANOS NO BRASIL: O QUILOMBO CAMPO GRANDE}

A entrada dos bandeirantes marcou a expulsão dos povos indígenas que se encontravam no Sul de Minas, dando início a uma nova forma de 
povoamento. Com o desenvolvimento das fazendas de produção agrícola, a chegada dos povos africanos também transformou as paisagens, os costumes, a economia e construíram a história desta região. Oriundos de diferentes lugares do continente africano, os benguelas, congos, angolas, minas, moçambiques e monjolos estavam entre os principais grupos de origem africana que tiveram Minas Gerais como destino (MARTINS, 2008, p.238). Além disso, a diversidade de povos deu origem a uma sociedade mestiça formada a partir de brancos de origem europeia; negros, vindos da África e indígenas, que já habitavam nossas terras. Da relação entre eles surgiram os pardos e mamelucos.

Infelizmente, nessa convivência, os "senhores" brancos buscavam exercer o domínio sobre os negros e indígenas. Para fugir dos maus tratos e poder viver em liberdade, muitos escravizados que conseguiam deixar as senzalas se refugiavam em locais chamados quilombos.

De acordo com Martins (2008, p.458), uma das primeiras fundações, em 1726, foi a do Quilombo ou "Povoação" do Ambrósio, localizado próximo ao rio Grande, onde hoje se encontra o município de Cristais (MG). Esse quilombo era formado por indígenas e negros fugitivos das "Vilas de Ouro" e recebeu esse nome em referência ao líder negro Ambrósio. Por ter conseguido a alforria, ele era reconhecido como responsável por todos os quilombos da região, formando uma grande Confederação quilombola, a de Campo Grande.

Campo Grande correspondia há dezenas de quilombos no Sul de Minas que foram destruídos em diversas batalhas comandadas pelo português Antônio Francisco França, entre 1743 e 1760. O mapa da figura 4, de 1763, mostra o vale do rio Grande (o rio principal que corta a carta na parte central) e alguns de seus afluentes, como o Sapucaí e o Verde, próximos à cidade de Alfenas atualmente.

Esses quilombos foram destruídos pelas tropas coloniais no século XVIII, restando poucos vestígios nos dias de hoje. Lembrando que Minas Gerais utilizou intensamente a mão de obra escrava na exploração de ouro e na 
produção agrícola, tornando-o um dos estados brasileiros com maior concentração de população negra e escravizada ao longo do século XIX. Embora existam poucas comunidades quilombolas oficialmente demarcadas, a presença de afrodescendentes é grande no Sul de Minas. De acordo com a Base de Informações Geográficas e Estatísticas do IBGE (2019), Minas Gerais é o segundo estado com mais territórios, agrupamentos ou localidades quilombolas, com pouco mais de mil comunidades (Figuras 2 e 3), duas delas situadas em Alfenas: Alfredo Manso e Pontinha.

Figura 2. Total de Comunidades Quilombolas no Brasil, por Estado (2019) 


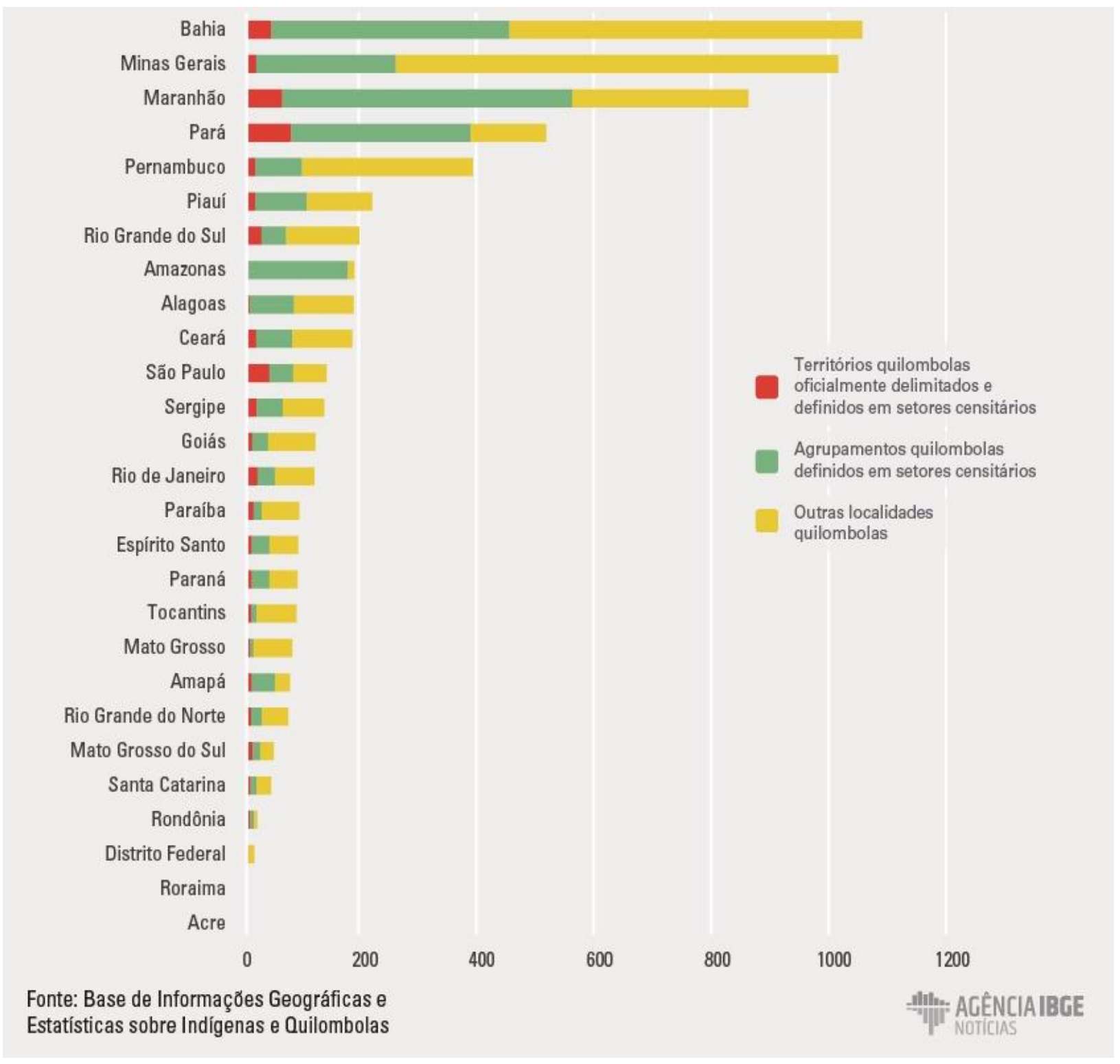

Fonte: IBGE. Disponível em: Acesso em 25 nov. 2021. Disponível em: < https://dadosgeociencias.ibge.gov.br/portal/apps/sites/\#/indigenas-e-quilombolas>.

Figura 3 - Comunidades Quilombolas em Minas Gerais (2019) 


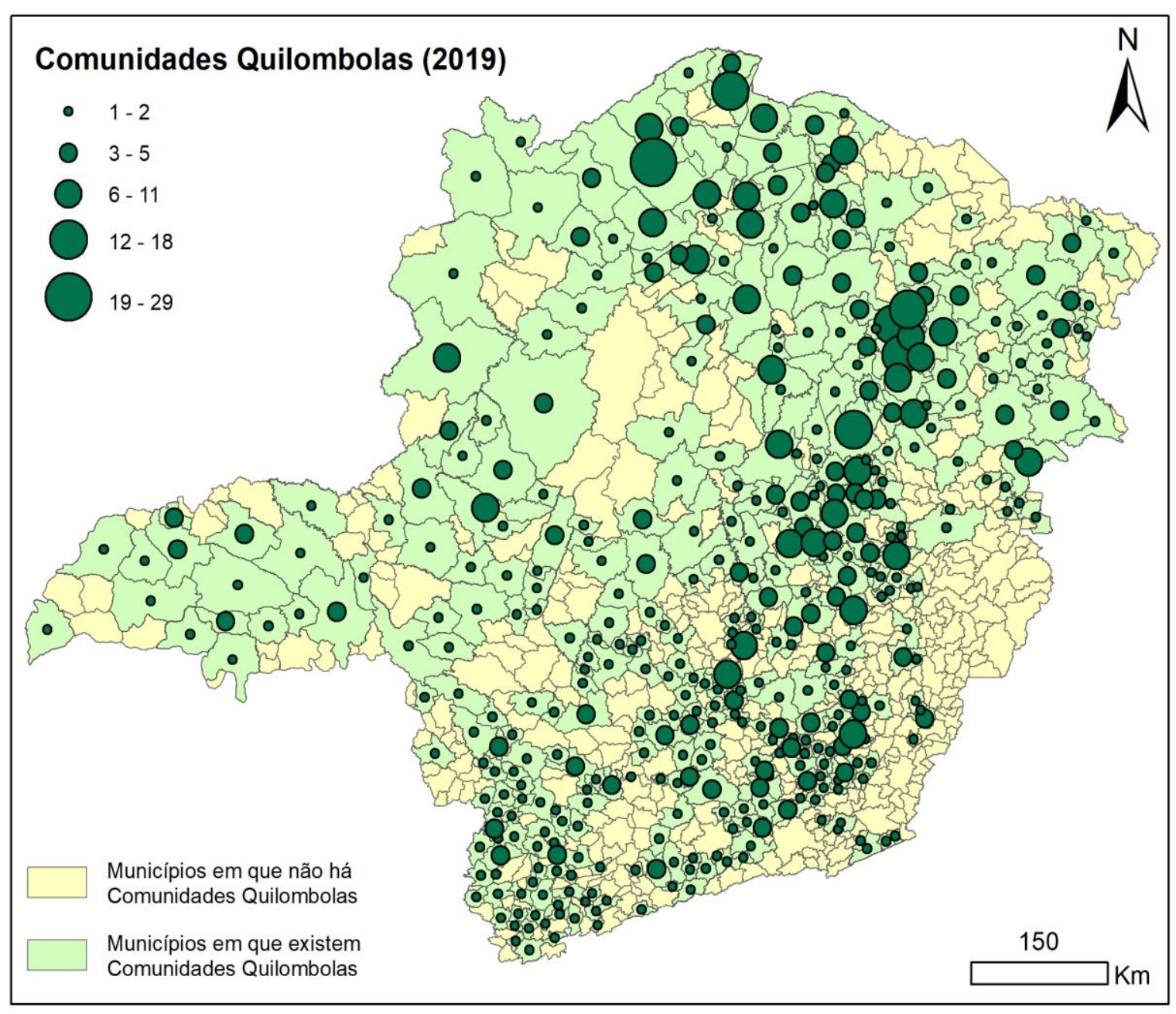

Fonte: Instituto Brasileiro de Geografia e Estatística (IBGE). Disponível em: https://dadosgeociencias.ibge.gov.br/portal/apps/sites/\#/quilombolas/app/cd63f556dd5 4481fa0584cf7cadccaa5.

\section{METODOLOGIA DE ADAPTAÇÃO}

Com base nos dados adquiridos a partir dos levantamentos bibliográficos acerca dos povos africanos, o "Mappa de todo o Campo Grande, tanto da parte da Conquista, que parte com a campanha do Rio Verde e S. Paulo como de Piuhy Cabeceiras do rio S. Francisco e Goyazes" foi escolhido por contemplar não só o município de Alfenas, mas grande parte do Sul do estado de Minas Gerais.

O mapa digitalizado foi obtido a partir do Arquivo Público do Distrito Federal (ArPDF). Criado em 1985, pelo Decreto $n^{\circ}$ 8.530, o acervo reúne documentos textuais, audiovisuais, cartográficos, entre outros de interesse 
público e que competem à Capital Federal (ArPDF, 2021). Com esse objeto cartográfico do século XVIII (Figura 4), buscamos identificar os principais acidentes geográficos e localidades presentes na carta. Partimos das denominações que se assemelham com as atuais, como o rio Grande e alguns de seus afluentes, como o rios Sapucaí e Verde; além das serras da Canastra e Boa Esperança.

Figura 4. Mappa de todo o Campo Grande, tanto da parte da conquista que parte com a campanha do rio Verde e S Paulo, como de Piuhy Cabeceiras do S.

$$
\text { Francisco e Goyazes }
$$

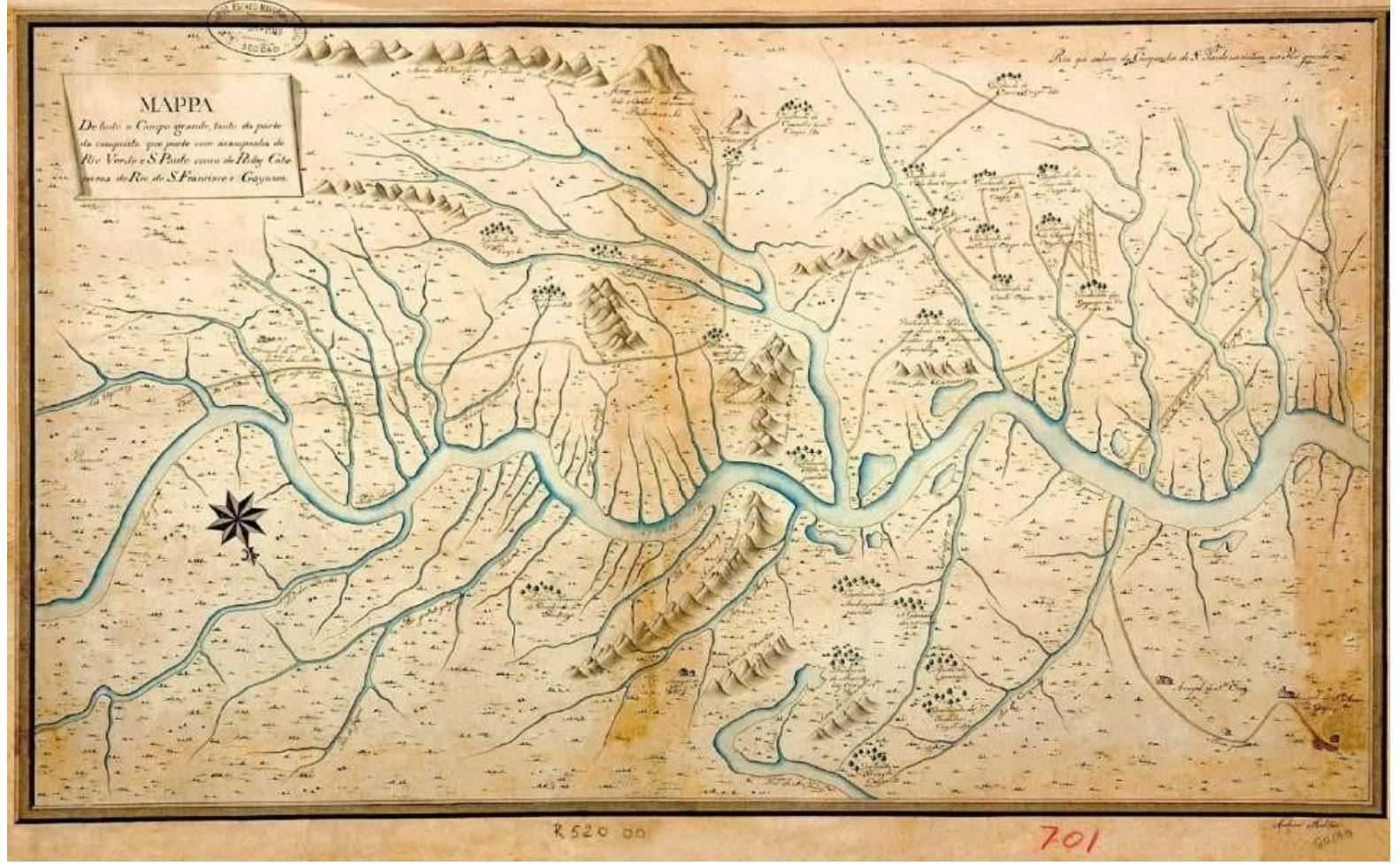

Fonte: Mapa do capitão Antônio Francisco França feito entre 1760 e 1763 - Coleção da Família Almeida Prado - Instituto de Estudos Brasileiros/USP - foto de 1992/ Tarcísio José Martins.

Arquivo Público do Distrito Federal (ArPDF), 2021. Disponível em: < https://www.arpdf.df.gov.br/mapa-de-todo-o-campo-grande-cabeceiras-do-rio-de-saofrancisco-e-goiazes/

O fato de a carta não ser precisa quanto à escala e às distâncias, exigiu um esforço maior para a identificação de outros pontos de referência. Foi o caso de um oiteiro, na parte de cima do mapa, denominado apenas de "Morro mais alto". 
Comparando com as cartas topográficas e hipsométricas atuais, concluímos tratar-se do dique anelar da caldeira de Poços de Caldas, também denominado serra de São Domingos. Assim, para tornar o registro cartográfico visualmente inteligível àqueles que estarão iniciando o processo de alfabetização cartográfica nas escolas, foi admitido alguns ajustes, realçando algumas toponímias atuais e identificando outras.

Para promover essa adaptação no mapa, utilizamos o software Adobe Photoshop, versão 22.4.3 de 2021. O programa oferece recursos para edição de imagens, aos quais foram definidas quatro etapas, sendo elas: recorte; seleção de elementos; correção de imperfeições e adição de elementos textuais. Em síntese, primeiro utilizamos a ferramenta "corte demarcado" para redimensionar e acentuar a área de interesse que contempla a proximidade com a Mesorerregião do Sul-Sudoeste de Minas Gerais.

Após recortar a imagem, o passo seguinte foi introduzir uma cópia do mapa original para criar camadas secundárias de um quadro semelhante a um pergaminho - identificado na figura 5 com (A); e do norte geográfico, pois este mapa tem o norte voltado para a parte de baixo do mapa, conforme a letra (B). A ferramenta "laço poligonal" foi aplicada para selecionar as respectivas representações. Optamos em manter o mapa suleado, tendo em vista a possibilidade de questionar a convenção hegemônica atual que determina que os mapas sejam representados com o norte voltado para cima. 
Figura 5. Captura de tela dos procedimentos adotados no Adobe Photoshop para seleção dos elementos cartográficos

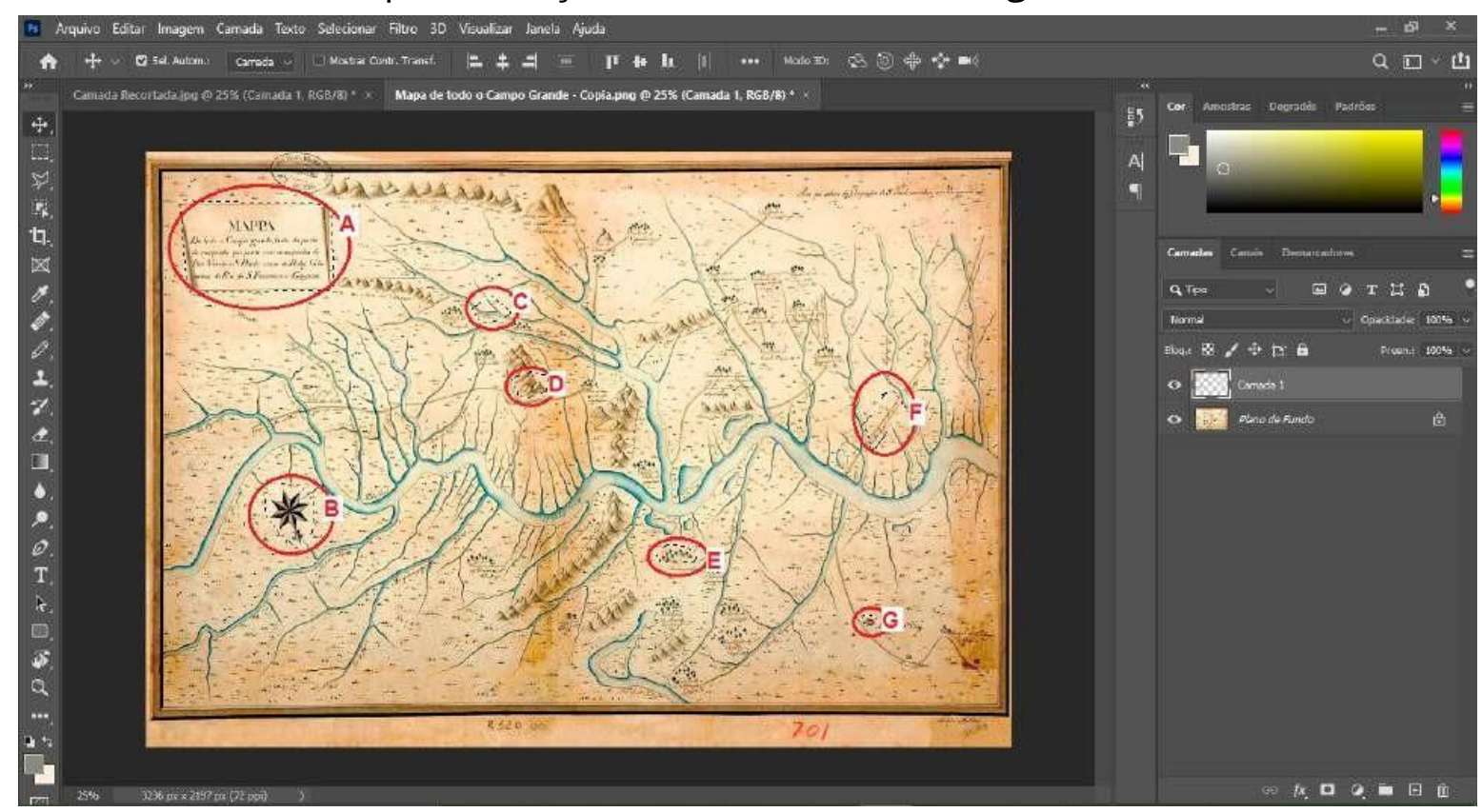

Fonte: Elaborado pelos autores.

Do mesmo modo, os elementos referentes aos "Rios e Ribeirões" (C); "Serras e Morros" (D); "Quilombos" (D); "Estradas" (F) e "Arraial" (G) foram submetidos ao mesmo procedimento para que compusessem a legenda adaptada através do "quadro semelhante a um pergaminho".

Em seguida, a ferramenta "pincel de recuperação" foi manipulada para corrigir imperfeições trazidas dos elementos selecionados e sobrepostos ao produto da camada inicialmente recortada. Por fim, foram introduzidos novos textos ao mapa para evidenciar nomenclaturas das representações, uma vez que a digitalização do mapa original resultou em um grau elevado de dificuldade na leitura.

Quanto à fonte do texto, adotou-se a fonte cursiva, tendo em vista a similaridade com a do texto original presente na carta (Figura 6).

Figura 6. Recorte comparativo do mapa original digitalizado com o adaptado 


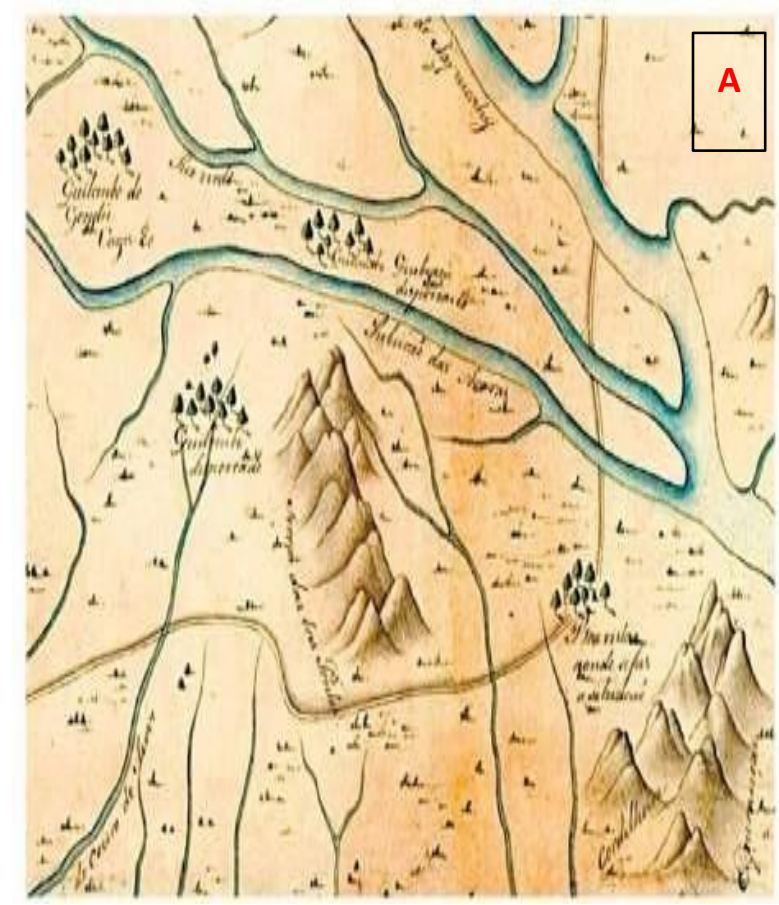

a) Recorte original

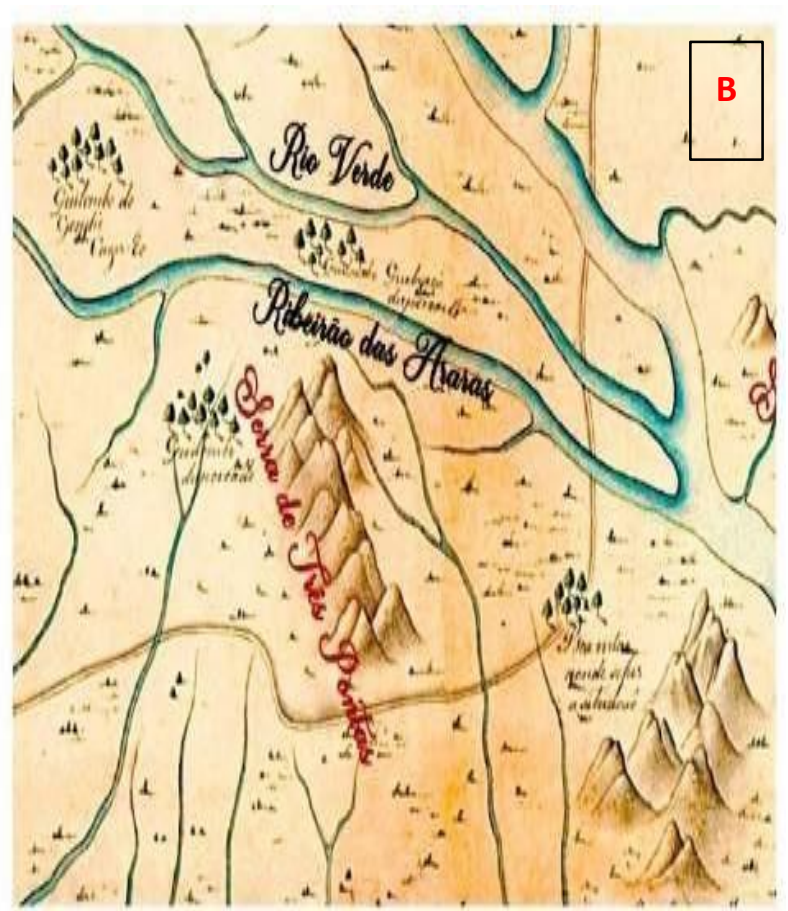

b) Recorte adaptado.

Fonte: Elaborado pelos autores.

\section{RESULTADOS E DISCUSSÕES}

Filnalizadas as etapas de edição de imagem, o produto final adaptado resultou no mapa expresso na Figura 7.

A adaptação do mapa buscou, portanto, torná-lo tangível àqueles que encontrariam maiores dificuldades em sua leitura e interpretação, dada à etapa escolar que se encontram (Ensino Fundamental). Destarte, o escopo da premissa busca tornar a linguagem cartográfica uma ferramenta de estímulo ao raciocínio geográfico.

Figura 7. Mappa de todo o Campo Grande, tanto da parte da conquista que parte com a campanha do rio Verde e S Paulo, como de Piuhy Cabeceiras do S.

Francisco e Goyazes (adaptado) 


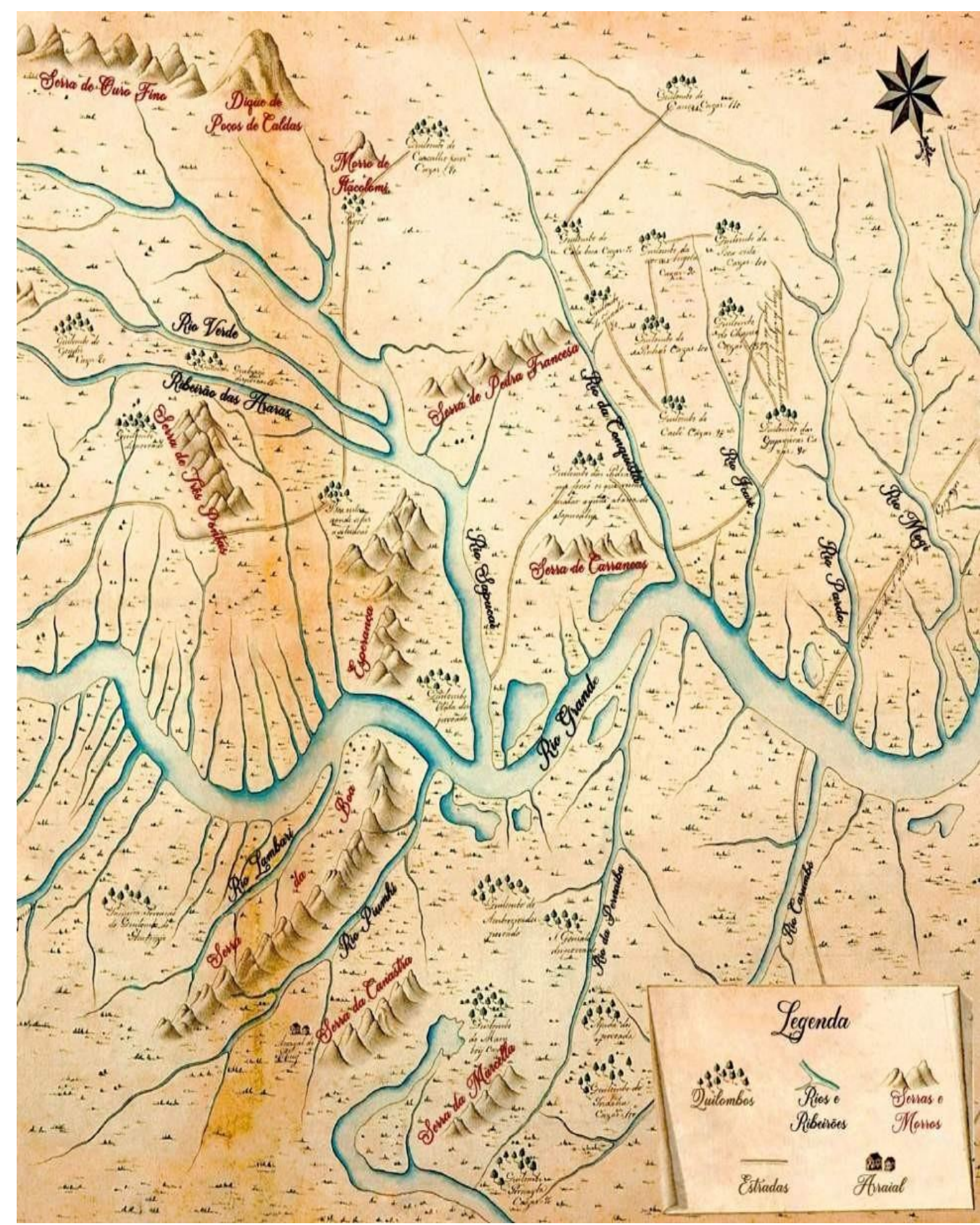

Fonte: Vitiello e Santos Júnior (2021, p. 27)

Espera-se que os alunos e as alunas possam experenciar o prazer da descoberta e se identificar com o lugar, a região e as paisagens representadas no mapa. Assim, almeja-se que tal estudo seja parte integrante de ações 
transformadoras tanto para discentes quanto para docentes que realizarão a leitura desse objeto cartográfico.

\section{CONSIDERAÇÕES FINAIS}

O presente estudo buscou resgatar um importante registro histórico e cartográfico ao adaptar o “Mappa de todo o Campo Grande, cabeceiras do rio S. Francisco e Goyazes", como uma alternativa de tornar a linguagem cartográfica acessível a um maior número de pessoas. Entretanto, ao refletir sobre o impacto causado pela abordagem do tema no Atlas Escolar Geográfico, Histórico e Cultural de Alfenas, o processo de adaptação se tornou complementar a sua visibilidade.

A necessidade da abordagem do assunto, em um movimento oposto ao de seu silenciamento, faz do estudo uma ação afirmativa e antirracista, para dirimir parte do apagamento dos povos africanos ao longo de nossa história. 0 recorte regional evidenciado pelas pesquisas e a linguagem facilitada do mapa revelam um tema raramente abordado em sala de aula. Ele proporciona aos novos leitores e leitoras a identificação e o pertencimento de estudantes e residentes do município com seu espaço geográfico, seus movimentos de lutas e resistências. Além de atender a prerrogativa legal que torna obrigatório o ensino de História e Cultura Afro-Brasileira e Indígena em todas as escolas brasileiras, públicas e privadas, do Ensino Fundamental e Médio (Lei 11.645/08).

Por fim, ressaltamos que através de técnicas simples de edição de imagens, um mapa histórico pode se tornar uma ferramenta de transformação da realidade vivida pelos alunos. A Cartografia Escolar possui os artifícios essenciais para aproximar os estudantes de temas não discutidos em sala de aula. Segundo Paulo Freire, em sua obra Pedagogia do Oprimido (1987), a “Educação não transforma o mundo. Educação muda pessoas. Pessoas 
transformam o mundo". Dessa forma, a metodologia de adaptação cartográfica alicerçada a um tema há muito silenciado corrobora para a reflexão, para o questionamento, para a mudança e para a desconstrução de estigmas, preconceitos e discriminação.

Assim, o ensino de Geografia, alicerçado ao movimento antirracista, confere uma possibilidade eficaz e praticável, iniciada por pequenas ações como a de adaptação de mapas. O conhecimento sobre o passado, as origens da herança histórica dos povos africanos e a discussão de pautas pouco debatidas devem ser estimuladas frente ao cotidiano escolar do ensino de Geografia. A subversão das desigualdades sociais, raciais e culturais através do diálogo e da reflexão crítica não se dará senão através de novas percepções e abertura de possibilidades contra hegemônicas.

\section{REFERÊNCIAS BIBLIOGRÁFICAS}

BRASIL. Poder Executivo. Lei 11.645/2008 de 10 de março de 2008. Brasília: Diário Oficial daUnião, 2008.

CEDEFES. Centro de Documentação Eloy Ferreira da Silva. Comunidades Quilombolas em Minas Gerais. Disponível em: https://www.cedefes.org.br/quilombolas-destaque/. Acesso em 02 ago. 2021.

DISTRITO FEDERAL. Arquivo Público do Distrito Federal. Mapa de todo o Campo Grande, cabeceiras do rio de São Francisco e Goiazes. Brasília, DF: ArPDF, c2021. Disponível em: https://www.arpdf.df.gov.br/mapa-de-todo-ocampo-grande-cabeceiras-do-rio-de-sao-francisco-e-goiazes/. Acesso em: 12 out. 2021.

FREIRE, Paulo. Pedagogia do Oprimido. Rio de Janeiro: Paz e Terra, 1987. 256 p.

FREITAS, Edilson Pereira de. Uma análise do ensino de Geografia utilizando as representações cartográficas no $2^{\circ}$ ciclo nas escolas públicas de Natal-RN. 2005. 120 p. Dissertação (Mestrado em Geografia) - Universidade Federal do Rio Grande do Norte, 2005.2 Disponível em: 
https://repositorio.ufrn.br/jspui/bitstream/123456789/18881/1/EdilsonPF.pdf. Acesso em: 12 out. 2021.

IBGE - Instituto Brasileiro de Geografia e Estatística. Base de Informações sobre os Povos Indígenas e Quilombolas. Brasília (DF): IBGE, 2019. Disponível em: https://www.ibge.gov.br/geociencias/organizacao-do-territorio/tipologias-doterritorio/27480-base-de-informacoes-sobre-os-povos-indigenas-equilombolas.html?=\&t=downloads. Acesso em: 12 out.2021.

JOLY, Fernand. A Cartografia. Campinas: Papirus, 1990.

MARTINS, Tarcísio José. Quilombo do Campo Grande: a história que se devolve ao povo.139.2.44, 2 ed. Contagem, MG: Santa Clara, 2008

SANTOS, Renato Emerson dos. Disputas cartográficas e lutas sociais: representações espaciaise jogos de poder. In: XII Colóquio de Geocrítica. Bogotá: Bolívia, 2016, p. $\quad 1-16$. Disponível em: http://www.ub.edu/geocrit/coloquio2012/actas/16.

VITIELLO, Márcio Abondanza e SANTOS JÚNIOR, Luiz Carlos. Atlas escolar geográfico, histórico e cultural de Alfenas. Goiânia: C\&A Alfa Comunicação, 2021. 